\title{
Jurisdição, Hegemonia e Integridade: Uma Visão Pós-Estruturalista sobre o Direito e sua Relação com a Sociedade e a Política no Brasil*
}

\author{
Igor Suzano Machado
}

Professor da Universidade Federal de Viçosa, Minas Gerais, Brasil

\section{INTRODUÇÃO: UMA VISÃO PÓS-ESTRUTURALISTA DO DIREITO E NOVAS FIGURAS DE LINGUAGEM PARA UM ROMANCE BEM CONHECIDO}

odemos, como Claude Lefort fez a respeito da política democráti-
ca contemporânea, reconhecer o direito contemporâneo como um sistema judicial que torna explícita a contingência de suas próprias fundações, sendo, portanto, radicalmente aberto ao confronto de vários esforços para representar a unidade do sistema. O próprio Lefort explicita que, não só a política, mas também o saber e o Direito ${ }^{1}$ teriam perdido sua essência fundadora, de forma que, atualmente, a autonomia do direito estaria ligada à impossibilidade de lhe fixar uma essência, descortinando um desenvolvimento do direito sempre dependente de um debate acerca de seus fundamentos (Lefort, 1986:28-29). Ou seja, assumindo essa premissa de Claude Lefort, assimilada pelo pensamento social e político de Ernesto Laclau e Chantal Mouffe, principais autores nos quais basearei minha argumentação no artigo, podemos entender o direito atual sobre a base de uma outra ontologia: não a ontologia de identidades objetivas e positivas que podem determinar a

\footnotetext{
* Gostaria de agradecer à Coordenação de Aperfeiçoamento de Pessoal de Nível Superior (Capes) (Proc.: BEX 2181/10-0) pela bolsa que me permitiu passar parte de meus estudos de doutorado em uma instituição estrangeira, e ao Departamento de Governo da Universidade de Essex que me aceitou como estudante visitante. Agradeço também à Fundação Carlos Chagas Filho de Amparo à Pesquisa do Estado do Rio de Janeiro (Faperj) pela bolsa de doutorado no Brasil.
}

DADOS - Revista de Ciências Sociais, Rio de Janeiro, vol. 56, no-4, 2013, pp. 943 a 974. 
direção do desenvolvimento jurídico sob o signo da necessidade, mas com base numa ontologia que reconhece a impossibilidade de uma fundação transcendental das formações discursivas, compreendendo os desenvolvimentos jurídicos como discursos jurídicos e, portanto, sob o signo de articulações contingentes.

Esta é a proposta do presente artigo: a compreensão da crise do direito contemporâneo como uma oportunidade para entender esse direito como uma estrutura descentralizada que, enquanto tal, pode ser analisada mediante uma abordagem pós-estruturalista. E esta abordagem pós-estruturalista, a ser utilizada aqui, será a teoria do discurso desenvolvida por Ernesto Laclau e Chantal Mouffe, especialmente em seu trabalho conjunto em Hegemonia y estrategia socialista: hacia una radicalización de la democracia (2006).

Laclau e Mouffe têm como pressuposto o axioma estruturalista de que todas as identidades são relacionais e construídas negativamente. Por exemplo, a palavra pai só faz sentido em contraste com as palavras filho, filha, mãe etc. E não só a palavra, mas também o papel do pai só faz sentido em contraste com os papéis de filho, filha, mãe etc. (Laclau, 2000:123). No entanto, os autores negam que, a partir deste conjunto de relações diferenciais, poderia resultar uma estrutura fechada, com um centro que a transcende, sendo capaz de determinar a sua estruturação sem se ser, por sua vez, determinado pela estrutura. O centro é suposto, ao mesmo tempo, como dentro e fora da estrutura e este paradoxo não pode ser representado por uma presença plena. Portanto, alegam os autores, temos de começar a pensar na ausência do centro, o centro não como um lugar fixo, mas como um não-lugar em que um número infinito de substituições pode ocorrer. E "na ausência de um centro ou origem tudo se torna discurso" (Derrida apud Torfing, 1999:40).

Neste contexto, devemos entender a sociedade não como sendo estruturalmente condicionada, mas como sendo discursivamente informada. É por isto que Laclau e Mouffe compreendem a sociedade como uma construção discursiva: uma estrutura irremediavelmente aberta e descentralizada, caracterizada por sua regularidade "na dispersão" (Foucault, 2007); um conjunto de diferenças que, em contextos de exterioridade, pode se tornar significativo como um todo (Laclau e Mouffe, 2006:143-144). Assim, a sociedade não pode ser nem uma objetividade pressuposta, nem um tipo de estrutura determinada pelo seu centro. Se abandonarmos Deus, o homem, a razão ou a economia como possíveis centros da estrutura da sociedade, devemos compreender a socie- 
dade como uma construção discursiva, como fazem Laclau e Mouffe. E, quanto ao tema deste artigo, se abandonarmos Deus (fonte, por exemplo, de integração de um direito divinamente concedido), a natureza (fonte, por exemplo, de integração de um direito de fundamento jusnaturalista), a razão (fonte, por exemplo, de integração de um direito de fundamento contratualista) e a aplicação silogística das leis do Estado (fonte, por exemplo, de um direito de fundamentação formalista) como centros possíveis da estrutura da Direito, devemos também compreender o Direito como uma construção discursiva, baseandonos, para isto, na ontologia social proposta nas obras destes dois autores.

Sendo assim, tomo como ponto de partida, neste artigo, a concepção de Direito não metafísica assumida pelo Barão de Monstesquieu quando da formulação de sua teoria de separação de poderes, ainda bastante influente nos desenhos institucionais das democracias contemporâneas. Presumindo a crítica deste modelo a noções metafísicas que encontram a fonte do Direito para além da atividade política - como nos modelos jusnaturalistas -, destaco também os problemas de um modelo de compreensão formalista e legalista do Direito, em que o centro unificador do sistema jurídico residiria numa aplicação silogística das leis formuladas pelo poder Legislativo ${ }^{2}$. Tendo isto em vista, inicio a abordagem acerca da crise do dirteito contemporâneo pela crise da catacrese $^{3}$ de Montesquieu (2001:180), em que o juiz é a "boca que pronuncia as palavras da lei".

Isto porque esta catacrese depende, por sua vez, de uma prosopeia ${ }^{4}$ : "a lei fala" e só precisa de uma boca para ser ouvida. No entanto, se a lei não fala, o que resta da sua boca? Se seguimos, por exemplo, Antoine Garapon (2001:40-41), e aceitamos que a lei já não é suficiente para orientar os juízes em sua tomada de decisão, como podemos manter a catacrese de Montesquieu? Sem a prosopopeia que a fundamenta, a catacrese de Montesquieu não sobrevive. Portanto, num contexto em que os juízes interferem cada vez mais na política e assumem cada vez mais posições políticas, devendo dar significado concreto a valores constitucionais abstratos, como liberdade e igualdade, não poderíamos manter a fé na catacrese de Montesquieu enquanto melhor maneira de compreender o Direito atual ${ }^{5}$.

Em vez desta catacrese, aponto outras figuras de linguagem que seriam melhores fontes para a caracterização da atividade judicial contemporânea. Refiro-me à metonímia e à sinédoque ${ }^{6}$, que tomo empres- 
tadas da teoria do discurso de Ernesto Laclau e Chantal Mouffe. Estas duas figuras de linguagem nos permitiriam compreender como, nas decisões judiciais atuais, tal qual no discurso dos partidos políticos e movimentos sociais, um grupo social específico representa a universalidade, unificando uma cadeia de significados em torno de um significante vazio $^{7}$, como a justiça, a igualdade, ou a liberdade ${ }^{8}$. Consequentemente, em um contexto de judicialização da política e politização da justiça ${ }^{9}$, destaco que uma teoria social como a teoria do discurso de Laclau e Mouffe pode ser uma importante referência teórica para reflexões sobre o direito contemporâneo. O objetivo deste trabalho é vincular esta abordagem teórica e este objeto empírico.

No entanto, como o trabalho teórico de Laclau e Mouffe mantém seu foco no plano ontológico, é necessário conectar suas reflexões ontológicas a manifestações do Direito no nível ôntico ${ }^{10}$, desenvolvendo teorias discursivas de médio alcance para três dimensões do fenômeno jurídico: 1) as instituições jurídicas e sua relação com o ambiente sociopolítico, 2) a prática da jurisdição e da litigância, e 3) as decisões judiciais em si mesmas. Por razões que se tornarão mais claras ao longo do texto, para a ligação com a primeira dimensão, irei me apoiar no profícuo estudo sociológico do direito desenvolvido por Philippe Nonet e Philip Selznick em sua obra Law and Society in Transition: Toward Responsive Law (2010). Para a segunda, vou usar a teoria jurídica de Ronald Dworkin e sua reconstrução discursiva do direito como um "romance em cadeia"11. Finalmente, para a terceira, farei referência a algumas importantes decisões recentes do Judiciário brasileiro como objeto de análise empírica baseada nas referências teóricas anteriores.

\section{USANDO A TEORIA DO DISCURSO DE LACLAU E MOUFFE PARA COMPREENDER O DIREITO (I): A ARTICULAÇÃO DISCURSIVA DA SOCIEDADE}

Conforme salienta Laclau, o maior progresso alcançado pelo estruturalismo foi o reconhecimento do caráter relacional de toda identidade social, mas seu limite foi transformar essas relações em um sistema com inteligibilidade e existência objetivas e uma essência. É esta aceitação do axioma estruturalista da dimensão relacional de toda identidade, junto com a recusa de uma organização sistêmica dessas identidades em torno de um centro fixo, que são as características do pensamento de Laclau e Mouffe que permitem que eles sejam considerados pensadores pós-estruturalistas. Mas se é mantido o caráter relacional 
de todas as identidades e, ao mesmo tempo, é renunciada a fixação dessas identidades em um sistema, a sociedade se torna um jogo infinito de diferenças, isto é, o que, no sentido mais estrito do termo, pode ser chamado de discurso - abandonando, por suposto, o entendimento do discurso como algo ligado estritamente apenas à fala e à escrita (Laclau, 2000:104).

No entanto, uma formação discursiva não se caracteriza apenas pela impossibilidade de uma fixação final dos significados e pelo fluxo infinito das diferenças. Lado a lado à falta de fixação definitiva de significados, um discurso é sempre um esforço para produzir uma sutura que interrompa o fluxo das diferenças, criando um todo significativo e inteligível, embora provisório e precário. A impossibilidade de fixação definitiva dos significados implica que deve haver fixações parciais. Caso contrário, o fluxo das diferenças mesmo seria impossível: para diferir, subverter um significado, deve haver um significado. Se o social não pode ser fixado em uma realidade objetiva e a priori como a socieda$d e$, ainda assim ele existe como um esforço para produzir tal objeto impossíve ${ }^{12}$. Todo discurso é assim, uma tentativa de dominar o campo da discursividade, interrompendo o fluxo das diferenças e instituindo um centro (Laclau e Mouffe, 2006:152). Por conseguinte, se uma totalidade, como a sociedade, não pode ser uma pressuposição apriorística, no entanto ela deve ainda ser considerada como um horizonte (Laclau, 2007:95).

Portanto, um discurso deve articular os elementos do campo de discursividade, transformando-os em momentos de uma cadeia discursiva dotada de significado, que estabelece alguns pontos nodais. São esses pontos nodais, que reúnem e dão unidade a todos os momentos assimilados, que também acabam limitando a presença de novos elementos na cadeia discursiva. Finalmente, vale ressaltar que esta organização do discurso não será uma mediação que visa reconstruir um todo inicial que se perdeu (como Deus, a natureza ou a razão). Na verdade, ela é uma atividade construtiva radical de articulação que modifica o significado original que os elementos tinham antes de sua assimilação discursiva (Laclau e Mouffe, 2006:142-153).

Por exemplo, o formalismo jurídico legalista articula uma série de elementos como a racionalidade, a equidade e a imparcialidade, reunindo-os em torno do ponto nodal da aplicação da lei. Estes elementos, após a assimilação, têm significados específicos que não são os mes- 
mos que eles teriam se situados fora deste discurso - por exemplo, a previsibilidade na estatística ou a equidade em um discurso político socialista poderiam significar algo completamente diferente - transformando-se, portanto, em momentos deste discurso. Um destes momentos é a aplicação silogística das leis do Estado, e este momento um ponto nodal - eleva-se acima dos demais, unificando suas equivalências - isto é, somente se poderia ter racionalidade, previsibilidade e equidade resultantes do Direito se o Direito mesmo não significasse mais do que a aplicação das leis do Estado. E este é também um ponto nodal que bloqueia a presença de outros elementos do discurso e interrompe a expansão infinita da cadeia discursiva - isto é, se o Direito é a aplicação de um sistema fechado de regras objetivas, ele não pode admitir ser também, por exemplo, o enunciado de preferências morais ou políticas de juízes particulares.

Contudo, o campo de discursividade contém uma grande quantidade de elementos, nem todos eles assimilados pelos discursos em momentos específicos, alguns deles flutuando entre diferentes discursos, e, como toda identidade é relacional, muitos deles funcionando como exteriores constitutivos dos demais. E se um exterior constitutivo é, em certa medida, "exterior", ele também é, igualmente, "constitutivo". A consequência disto é uma dimensão inextricável de contingência inerente a todas as identidades sociais. Como a fonte da possibilidade de todas as identidades sociais é também a fonte da obstrução da constituição de suas identidades como plenitudes objetivas, toda identidade é também uma fonte inesgotável de possíveis antagonismos (Laclau 2000:49). Isto significa que a articulação discursiva do exterior constitutivo não pode ser vista apenas como a origem da identidade, mas precisa ser vista também como o bloqueio de sua efetivação, como um inimigo que deve ser desafiado. E se não existe um centro para determinar a mediação discursiva sob a lógica da necessidade, o que resta é a possibilidade infinita de subversão e rearticulação discursiva das relações antagônicas sob a (não)lógica da contingência.

Voltando ao exemplo do Direito e sua possível análise com base nas categorias desenvolvidas por Laclau e Mouffe. No formalismo jurídico, o "justo" é articulado com uma ideia estritamente formal, e, portanto, universal, de justiça. A forma de aplicação da lei é o seu verdadeiro conteúdo jurídico e sua dimensão moral ou política é uma questão extrajurídica. Isto exclui qualquer discussão sobre justiça substantiva do momento de aplicação da lei: o conteúdo substantivo do Direito deve 
ser definido apenas pelo Legislativo. Neste contexto, a justiça formal se opõe à justiça substantiva e essa oposição oferece suporte à primeira como parâmetro do "justo" no formalismo jurídico. No entanto, é possível articular o "justo" necessariamente a uma noção de "justiça substantiva", como fazem vários discursos antiliberais. Assim, tomada como bloqueadora da afirmação de uma justiça substantiva, a justiça formal pode ser vista como sua força antagônica que deve ser confrontada e, consequentemente, um novo discurso de caracterização do Direito precisa ser articulado. E esta renovação discursiva não seria de forma alguma predeterminada. Ela poderia, por exemplo, assimilar elementos de um discurso econômico em um pragmatismo jurídico economicamente embasado ${ }^{13}$. Ou, então, buscar uma fundamentação do direito calcada numa unidade moral que extrapola a aplicação das regras legislativas como fim último do direito ${ }^{14}$.

\section{USANDO A TEORIA DO DISCURSO DE LACLAU E MOUFFE PARA COMPREENDER O DIREITO (II): O MOVIMENTO DE SINÉDOQUE DE HEGEMONIA POLÍTICA}

De acordo com o exposto até agora, pode-se inferir que a instituição do discurso, o estabelecimento de seus pontos nodais, a exclusão de seu exterior constitutivo e a articulação dos seus elementos como momentos diferenciais são operações baseadas no exercício do poder, excluindo e suprimindo as alternativas que são mantidas fora da cadeia discursiva. Isto faz com que a construção do fechamento precário e temporário da sociedade seja uma atividade política: uma atividade que usa o poder e a repressão como os únicos meios de lidar com a dimensão antagônica ontológica da vida social. Ainda assim, algumas destas exclusões e repressões estão tão profundamente assimiladas que seu caráter político é esquecido e elas se tornam momentos incontroversos de certos discursos, permitindo uma referência altamente estável para a ação. No trabalho de Laclau e Mouffe, esses momentos "naturalizados" dos discursos correspondem à dimensão do "social". Assim, uma diferença entre o político e o social é estabelecida e o político obtém precedência sobre o social, tornando-se sua dimensão de definição (Laclau 2000:50-51).

Mas Laclau e Mouffe também dedicam atenção à lógica específica da determinação política do social: o momento em que uma nova formação discursiva emerge para realizar uma nova sutura em uma fratura social, fornecendo-lhe uma totalidade significativa temporária. 
Enquanto o social é um processo de sedimentação, a política ${ }^{15}$ seria um processo de reativação. Este processo ocorre em um momento de deslocamento, em que os discursos disponíveis não conseguem emprestar sentido a novos eventos ou aspectos sociais. Neste ponto, cria-se uma situação instável em que a natureza contingente das formações discursivas é explicitada e seus elementos precisam ser rearticulados para formar uma nova cadeia significativa (Laclau, 2000:60). No exemplo das mudanças recentes no direito, pode ser considerado como um exemplo de deslocamento a dificuldade que uma compreensão jurídica formalista tem para assimilar em suas cadeias discursivas significativas as reivindicações morais das legislações pós-Holocausto e do Estado de bem-estar social e, consequentemente, a abertura dessas cadeias discursivas a rearticulações alternativas que possam dar conta desta nova realidade.

Importante é que a articulação política a ser produzida em um momento de deslocamento será uma articulação hegemônica, isto é, uma articulação em que uma particularidade ocupa o lugar do universal. Sem uma referência transcendental a ser mediada pelas práticas discursivas, esta referência será necessariamente uma particularidade, mas uma particularidade que pode tomar o lugar da universalidade num tipo de relação semelhante à relação de hegemonia em Gramsci, na qual uma classe social transcende os seus próprios interesses corporativos para representar um grupo social mais amplo (Laclau e Mouffe, 2006:13-14 $)^{16}$. Usando categorias da retórica, podemos dizer que a metonímia pode ser usada para expandir a cadeia discursiva de equivalências, articulando novas relações de contiguidade e um tipo específico de metonímia, a sinédoque, é particularmente representativo do movimento de hegemonia. Como uma sinédoque é uma metonímia em que a relação representada é uma de contiguidade entre o todo e uma de suas partes, a sinédoque é exatamente a representação retórica das relações de hegemonia.

O funcionamento da sinédoque das relações hegemônicas é possível porque a totalidade, embora não possa ser representada por uma identidade objetiva e positiva, pode ser simbolizada por alguns signos de uma plenitude ausente. Estes signos são significantes vazios, cujo excedente de significado os coloca fora do alcance de um conteúdo específi$\mathrm{Co}^{17}$. Por exemplo, em um contexto de desordem total, o significante "ordem" torna-se o sinal da plenitude ausente. Mas a "ordem" só existe como ordens específicas. Assim, embora represente uma dimensão 
universal da sociedade - a ausência causada pela desordem -, uma ordem social será sempre uma ordem específica, ou seja, uma particularidade - como uma ordem liberal, ou uma ordem conservadora (Laclau, 1996:44). Esta é a sinédoque da hegemonia: uma particularidade que, sem renunciar à sua particularidade, representa uma totalidade que a transcende, obviamente contaminada pela sua origem particular. E quando a determinação do significado do significante vazio está sob a pressão de duas ou mais cadeias discursivas diferenciais em nosso exemplo, discursos liberais e conservadores sobre a "ordem" - temos um significante flutuante, um significante que flutua entre discursos conflitantes em busca da hegemonia política (Laclau, 2004:302-305).

Voltando ao tema do Direito, especificamente, podemos considerar, por exemplo, os modelos do "positivismo jurídico inclusivo", do "direito como integridade" e do "pragmatismo jurídico economicamente orientado" como formações discursivas que competem por hegemonia no campo da teoria jurídica. Todos estes disursos poderiam falar sobre "justiça", um significante vazio que flutua entre os três discursos e faz referência à ausência de justiça como o problema do formalismo jurídico. Um positivista inclusivo poderia argumentar que a justiça é contígua à imparcialidade e a imparcialidade só seria possível através da restrição das normas jurídicas à legislação promulgada pelo Estado isto é, o direito posto -, e só por meio dessa legislação considerações morais poderiam adentrar no universo do Direito ${ }^{18}$. Por outro lado, um partidário do que Dworkin chamou de direito como integridade poderia argumentar que a justiça é contígua à integridade moral, ampliando o conjunto de normas jurídicas aos princípios morais, mesmo que estes princípios não estejam explícitos na legislação ${ }^{19}$. Finalmente, um pragmatista econômico poderia dizer que a justiça é contígua ao aumento da riqueza e que esta deve ser a única referência para qualquer decisão judicial ${ }^{20}$. A justiça não se limita a essas metonímias, mas só se torna efetiva como um tipo particular de justiça, como é o caso destes exemplos. Portanto, a "hegemonia" do discurso sobre o Direito só pode ser alcançada pela operação de sinédoque de chamar a justiça, por exemplo, ou de "imparcialidade", ou de "correção moral", ou de "aumento da riqueza".

Tendo em vista a explicação e os exemplos apresentados anteriormente, demonstrando a propriedade e a utilidade de uma abordagem para o Direito que se baseie em uma teoria do discurso, como proposta por 
Laclau e Mouffe, acredito que um direito descentrado pela crise dos fundamentos do formalismo jurídico poderia fazer uso de novas figuras de linguagem, especialmente a sinédoque - representação retórica da lógica de hegemonia - para substituir a catacrese de Montesquieu. Contudo, neste ponto é necessária uma observação.

Nas obras de Laclau, a catacrese é considerada o movimento retórico em si, isto é, o ato de nomear algo com um termo figurativo que não pode ser substituído por um literal, como em "perna da cadeira" (Laclau, 2007:96). Como essa função é realizada por qualquer figura de linguagem, prefiro considerar a catacrese como uma metáfora desgastada. Isto porque, nos seus primeiros usos, "a perna da cadeira" era uma metáfora, mas, após o desgaste causado pelo uso repetido, tornou-se uma metáfora já gasta, ou seja, uma catacrese. Portanto, a catacrese seria uma figura de linguagem mais próxima do social do que suas irmãs metáfora, metonímia, e sinédoque, mais explicitamente ligadas ao político ${ }^{21}$. Quando proponho a substituição da catacrese de Montesquieu por metáfora, metonímia e sinédoque, o que proponho é o reativação do caráter político e contingente da construção discursiva do Direito em todos os seus níveis.

\section{LIGANDO OS NÍVEIS ONTOLÓGICO, ÔNTICO E EMPÍRICO}

Como mencionado anteriormente, Laclau e Mouffe realizam suas reflexões intelectuais num nível ontológico. Por este motivo, Jacob Torfing, concluindo seu livro sobre a teoria do discurso de Laclau e Mouffe, diz que:

Embora os conceitos e argumentos das novas teorias do discurso tenham sido produzidos em contextos específicos de análise, eles foram lançados a um nível muito abstrato. Isto é, como a teoria do discurso tem uma natureza metateórica, é frequentemente difícil de aplicá-la de forma não mediada a estudos empíricos específicos. A teoria do discurso oferece uma compreensão básica dos aspectos fundamentais da formação discursiva do mundo, mas não tem a ambição de fornecer um quadro detalhado e totalmente operacionalizada para o estudo de todos os tipos de relações sociais, culturais ou políticas. Assim, gostaria de alertar contra as tentativas de aplicar a teoria do discurso direto e instrumentalmente a estudos empíricos (Torfing, 1999:291; tradução livre).

Esta é a razão pela qual David Howarth afirma que a noção de articulação desenvolvida por Laclau poderia ser estendida para um nível des- 
critivo e explicativo, sendo um excelente ponto de partida para a ligação entre os níveis ôntico e ontológico, sem subsumir o concreto ao abstrato e sem retornar a um empirismo vazio de fundamentos teóricos. No entanto, continua Howarth, isto exigiria o desenvolvimento de um conjunto de conceitos e teorias de "médio alcance" sobre as instituições políticas e as organizações econômicas localizadas em contextos históricos específicos (Howarth, 2004:267). Portanto, para cumprir a tarefa de tornar possível a vinculação da teoria do discurso a estudos empíricos sobre o direito contemporâneo, resta necessário desenvolver, ou trazer à discussão, alguns "conceitos e teorias de médio calcance" que tornariam isto possível. Não obstante, antes de me lançar a tal tarefa, gostaria de deixar claro em que níveis do Direito esta vinculação poderia acontecer e onde seria necessário desenvolver algumas observações sobre tal ponte ontológico-ôntica.

O primeiro nível corresponde ao nível teórico. Como a teoria do discurso é, de alguma forma, metateórica, com foco no plano ontológico, podemos utilizar seus conceitos para analisar várias novas teorias jurídicas que visam substituir ou reformar o enfoque do positivismo jurídico, tradicionalmente interessado na compreensão da norma jurídica por um prisma estritamente formal ${ }^{22}$. Por exemplo, podemos analisar como construções discursivas específicas as teorias jurídicas de autores como Luigi Ferrajoli (2009) e seu positivismo jurídico inclusivo, baseado no conceito de garantias, e Richard Posner (2007) e seu pragmatismo jurídico economicamente fundado. Meus exemplos anteriores de aplicação da teoria do discurso ao Direito focalizaram este nível.

No entanto, chamo a atenção para outros três níveis propriamente empíricos em que acredito que seria possível efetuar uma aproximação entre a teoria do discurso de Laclau e Mouffe e o Direito por meio de outras teorias mais específicas. Para isto, seguirei a intuição da escola de Birmingham, Norman Fairclough e Adrianus Teun van Dijk em seus estudos sobre meios de comunicação de massas com base em uma teoria do discurso, citados por Jacob Torfing em New Theories of Discourse: Laclau, Mouffe and Zizek (1999:212-213). De acordo com Torfing, a escola de Birmingham, Norman Fairclough e Teun Adrianus van Dijk não analisam o discurso sobre os meios de comunicação de massas ou o discurso dos meios de comunicação de massas, mas na realidade, os meios de comunicação de massas como discurso, distinguindo três níveis para esta análise empírica: o micro, o meso e o macro. 
No nível micro, os estudos discursivos sobre a mídia de massas deveriam se concentrar no texto, entendendo o termo em sentido amplo, incluindo sinais falados, escritos e materiais audiovisuais. No nível meso, a atenção deveria se concentrar em formas institucionais de produção, distribuição e consumo das mensagens dessas mídias e a intertextualidade produzida por essas "regras" de produção, distribuição e consumo. Finalmente, no nível macro, o que deve ser analisado são as práticas socioculturais que organizam o campo dos meios de comunicação como um todo, como as regras políticas e econômicas sobre a propriedade e controle desses meios (Torfing, 1999:213-215).

Acredito que podemos traçar um paralelo entre esta abordagem em três níveis discursivos para a mídia de massas e uma abordagem similar em três níveis discursivos para o Direito. No nível micro, o nível do "texto em si", poderíamos situar as decisões dos tribunais, as sentenças dos juízes ou as petições dos advogados. No nível meso, o nível das "formas institucionais de produção, distribuição e consumo", poderíamos localizar e regras e lógicas da jurisdição e da litigância. Finalmente, no nível macro, o nível das "práticas socioculturais que organizam o campo", poderíamos situar a relação entre as instituições jurídicas e o ambiente social e político. Em retrospectiva, podemos falar das instituições jurídicas (nível macro), jurisdição e litigância (nível meso) e decisão judicial ou petição judicial em si mesmas (nível micro).

Com esta distinção e reconhecimento destes três níveis, podemos encontrar algumas reflexões sobre o nível ôntico do Direito que têm afinidades com a teoria do discurso de Laclau e Mouffe e nos permitem realizar pesquisas empíricas com base na orientação ontológica e metateórica destes autores. Com relação ao nível macro, o nível das instituições judiciárias, sugiro que uma boa referência seja o trabalho de Philippe Nonet e Philip Selznick. No que se refere ao nível meso, da jurisdição e litigância, esta reflexão poderia ser encontrada na teoria jurídica de Ronald Dworkin. Finalmente, no nível micro, do texto da decisão ou petição judicial, uma análise textual das mesmas, com base nas reflexões teóricas anteriores, emergiria como o caminho ideal para sua análise empírica via teoria do discurso.

\section{DIREITO E SOCIEDADE EM TRANSIÇÃO NO NÍVEL MACRO: REFLEXÕES SOBRE AS INSTITUIÇÕES JUDICIAIS}

Em 1978, Philippe Nonet e Philip Selznick escreveram um profícuo livro chamado Law and Society in Transition: Toward Responsive Law 
(2010). Neste livro os autores desenvolvem uma interessante reflexão sociológica sobre a situação do direito e das instituições jurídicas dos Estados Unidos naquele momento. Como os Estados Unidos têm espalhado a sua influência política em todo o mundo, as questões tratadas no livro se tornaram referências importantes para um grande número de países que organizaram suas instituições políticas e jurídicas influenciados de alguma maneira pelo sistema norte-americano, de que é exemplo, inclusive, o Brasil. Fundamentalmente, Nonet e Selznick argumentam em seu livro que podemos classificar as instituições judiciais como instituições de um direito repressivo, autônomo ou responsivo.

Estas definições do direito correspondem a três tipos ideais que poderiam ser usados para classificar sistemas judiciais específicos, na medida em que suas características sejam identificadas em maior medida com o modelo repressivo, autônomo ou responsivo ${ }^{23}$. Estas características seriam reações ao ambiente sociopolítico em que as instituições judiciais estariam inseridas. No caso do Direito repressivo, o Judiciário estaria inserido em um contexto de consolidação da instância política. Portanto, suas instituições procurariam impor e manter uma ordem desejada pelas elites políticas e não por toda a comunidade (Nonet e Selznick, 2010:75).

Como a coerção e a manutenção da ordem são características de qualquer sistema judicial, o direito repressivo guarda semelhanças com qualquer sistema jurídico. Apesar disto, deve-se ter em mente que o Direito não se limita ao uso da coerção, mas, sim, combina este uso com uma reivindicação de legitimidade do poder político. E no que diz respeito à dimensão de ser uma instância de legitimação do poder político, o direito repressivo é, em grande medida, deficiente. É por isto que Nonet e Selznick apresentam, como uma evolução do direito repressivo, o direito autônomo, que tem como objetivo fornecer uma base mais sólida para a legitimidade do poder político em uma sociedade dotada de maior complexidade e diversidade (Nonet e Selznick, 2010:100).

O objetivo do direito autônomo, como uma evolução do modelo repressivo, seria estabelecer um governo das leis, em vez de um governo dos homens. No modelo autônomo, todos, governantes e governados, estão sujeitos à mesma ordem jurídica e sistema judicial. Esta natureza universal do seu "modelo de regras" proporciona ao direito autônomo os recursos necessários para a manutenção da legitimidade política em uma sociedade complexa. Ainda assim, a sua justiça estritamente for- 
mal e processual se mostrou incapaz de enfrentar algumas injustiças substantivas já fortemente sedimentadas.

Focando seus procedimentos e estando vinculado à obediência estrita às regras prescritas pelo legislador, um sistema judicial autônomo torna-se insensível às demandas sociais por justiça substantiva e sua autonomia degenera em isolamento. E se, por um lado, o direito repressivo, no seu desejo de manter a ordem, foi insensível à dimensão exigida pelo Direito de promover a legitimidade, por outro lado, o direito autônomo, com o objetivo de superar os problemas do direito repressivo, acabou negligenciando uma outra dimensão essencial para o Direito: a promoção da justiça.

Neste contexto, há uma demanda por um novo tipo de direito. Nonet e Selznick chamam este novo tipo de direito de direito responsivo. A transição do direito autônomo ao direito responsivo implica uma abertura das instituições judiciais ao seu meio ambiente, entendido como uma fonte de autocorreção. O modelo de regras é enfraquecido, a equidade não é mais cega para as desigualdades sociais e a desobediência nem sempre é considerada uma ofensa ao sistema jurídico (Nonet e Selznick, 2010:127).

A transformação e evolução sociológica do Direito, descrita por Nonet e Selznick como a transição do direito repressivo para o direito autônomo e do direito autônomo para o direito responsivo - lembrando que os três modelos são tipos ideais que não refletem as realidades empíricas com exatidão - possui consequências nas reflexões da teoria jurídica. Por exemplo, a transição entre o direito autônomo e o direito responsivo resultou na passagem de uma teoria jurídica positivista - focada no aspecto formal para a compreensão da identidade da norma jurídica - a uma teoria jurídica que tenta ir além do positivismo - seja num positivismo inclusivo, que busca ascrescentar às regras de reconhecimento da norma jurídica uma dimensão moral, seja numa versão mais abertamente antipositivista, como na teoria de Dworkin. Assim como argumentei que esta transformação da teoria jurídica pode ser entendida no âmbito de uma teoria do discurso, defendo que a transformação das instituições judiciais também pode. E o trabalho de Nonet e Selznick se apresenta como uma reflexão na qual isto pode ser observado.

Tendo isto em vista, acredito que as transições entre o direito repressivo, o direito autônomo e o direito responsivo podem ser descritas 
como uma rearticulação de elementos discursivos em novas cadeias de significado. Conforme foi dito, para Nonet e Selznick as noções de direito repressivo, autônomo e responsivo seriam reações do Direito ao ambiente sociopolítico em que as instituições judiciais estariam inseridas. Desta forma, a mudança e transição entre os modelos podem ser consideradas repostas a momentos de deslocamento, que, assim, são tentativas de reconstrução hegemônica, dotando o sistema de unidade por meio da elevação do que seria apenas um de seus elementos particulares como sendo a característica determinante da estrutura como um todo.

Isto é visto claramente na cadeia discursiva unificada sob o significante vazio "ordem" (no direito repressivo), que é subvertida por uma cadeia discursiva unificada sob o significante vazio "legitimidade" (no direito autônomo), destacando que o caminho reverso também pode ser feito, como é subentendido na noção de hegemonia de Laclau e Mouffe, e posto em destaque também por Nonet e Selznick, quando, apesar de sua postura abertamente evolucionista, no epílogo do seu livro destacam as formas como o "direito pode morrer" (Nonet e Selznick, 2010). É menos claro, no entanto, na transição entre o direito autônomo e o responsivo - talvez pelo sistema judicial responsivo ser mais do que o sistema judicial contemporâneo, sendo uma promessa ainda a ser alcançada. Mesmo assim, penso que isto se deve mais à abertura típica do direito responsivo que, em vez de dar ao Direito um novo princípio de fechamento, destaca a contingência deste princípio. De acordo com o pensamento de Claude Lefort, posto em destaque no início do artigo, assim como a política democrática, o direito responsivo explicitaria, em alguma medida, o caráter hegemônico - e contingente - da articulação de seu conteúdo.

\section{HEGEMONIA E INTEGRIDADE NO NÍVEL MESO: REFLEXÕES SOBRE A JURISDIÇÃO E A LITIGÂNCIA}

Conforme destacado no tópico anterior, a transição de um direito autônomo a um direito responsivo se reflete na transição de uma teoria jurídica positivista e formalista a uma teoria jurídica que tenta ir além do formalismo e positivismo. Na verdade, é possível compreender as reflexões teóricas contemporâneas sobre o Direito como uma tentativa de fornecer um quadro para que os operadores do direito possam desempenhar suas funções nas instituições judiciais de um direito responsivo. Estes quadros, conforme visto, podem variar desde manter a 
fé no modelo de regras positivista, a aceitar a atual abertura do sistema jurídico como um chamado para a transformação social radical operada por juízes, passando pela tentativa de reintegrar o sistema jurídico por meio de pressuposições morais de caráter universal.

Claro que existem outras opções de abordagens para o Direito além dessas citadas acima. Por exemplo, há teorias jurídicas pós-modernas, feministas e marxistas, que compartilhariam mais "bases comuns" com o pensamento de Laclau e Mouffe. O problema é que essas teorias geralmente dão demasiada atenção para a dimensão social do dissenso, negligenciando a importante dimensão de consenso, que encontra destaque tanto na noção de hegemonia de Laclau e Mouffe, quanto na noção de integridade em Dworkin. Daí um dos motivos pelos quais argumento que para a reconstrução pretendida neste trabalho, seria mais útil a noção de direito como integridade de Dworkin.

É sintomático deste problema nas teorias jurídicas de matriz feminista, marxista, multiculturalista e pós-modernista, a crítica às ideias de Dworkin empreendida pelos juristas pós-modernos Costas Douzinas e Ronnie Warrington. Eles criticam a dimensão da integridade do direito em Dworkin porque, segundo eles, ela seria uma espécie de sinédoque - isto é, fazendo parecer o todo o que é apenas uma das partes - e, consequentemente, uma espécie de farsa (Warrington, Douzinas e McVeigh, 1991:66-67). O que eles, assim como outros juristas que focam a diversidade e o dissenso entre diferentes classes, gêneros e culturas, não conseguem entender, diferentemente de Laclau e Mouffe, é que este movimento de sinédoque não é uma farsa, mas uma característica necessária da disputa política.

Também o positivismo e o pragmatismo jurídicos, referenciados anteriormente, podem ser considerados teorias que, da mesma maneira que o pós-modernismo, feminismo e marxismo jurídicos, são céticas quanto a uma dimensão universal de fundamentação do Direito. Neste sentido, a mesma crítica é válida para destacar a inadequação destas teorias para uma compreensão do Direito com base na noção de hegemonia de Laclau e Mouffe, que, se por um lado, é uma noção que também deriva de uma concepção cética a respeito de uma moral universal, por outro, nega essa universalidade moral de maneira bastante peculiar: rechaça tal universalidade como ponto de partida, mas a assume como um horizonte, negando-a, por conseguinte, num nível ontológico - do político - apenas pata destacar sua necessidade num nível 
ôntico - da política e do social - em que estariam inseridas as práticas judiciais. Por tudo isto, por mais controverso que possa parecer à primeira vista, enquanto interpretação da prática jurídica mais afeta a um entendimento de acordo com a teoria de discurso de Laclau e Mouffe, farei uso aqui da teoria do direito como integridade de Dworkin.

Quanto à teoria de Dworkin, sua sugestão é que a jurisdição deve ser entendida como um empreendimento interpretativo que busca materializar os valores de uma comunidade política ligada fraternalmente por princípios morais. A substância utilizada para executar esta tarefa é a cultura institucional da comunidade, ou seja, suas decisões políticas passadas. Ao lidar com um caso judicial específico, os agentes envolvidos no julgamento devem ver nas decisões políticas do passado não apenas as regras a serem aplicadas, mas também os princípios a serem concretizados. E estes princípios podem exigir a revisão de algumas regras que poderiam miná-los e a aceitação de outras que, mesmo não estando explícitas na legislação, seriam necessárias para a efetivação destes mesmos princípios (Dworkin, 2003).

A atividade judicial dentro deste contexto seria exatamente fornecer um significado concreto para os princípios derivados dos metaprincípios da igualdade e liberdade. $\mathrm{E}$ a fonte para a construção das cadeias significativas que devem preencher os significantes igualdade e liberdade com significados específicos seria a cultura institucional da comunidade, ou seja, suas decisões políticas passadas - como leis, precedentes judiciais etc. - o que faz com que a atividade judicial, tal como vista por Dworkin, de acordo com a interpretação utilizada neste trabalho, possa ser entendida como uma prática de articulação de elementos discursivos para a composição de uma nova totalidade coerente que ele vai chamar exatamente de um romance: o romance em cadeia que ele argumenta que os juízes escrevem cada um, um capítulo, por meio de suas decisões ${ }^{24}$.

Sobre a política entendida num quadro de teoria do discurso, Jacob Torfing diz que:

O contexto estrutural de significado e ação contém numerosas regras. Estas não são nem rígidas nem apriorísticas, mas flexíveis, e, em última instância, simplesmente um exemplo do seu uso. No entanto, elas não podem ser alteradas de forma arbitrária, mas têm de hegemonizar, em certa medida, os casos anteriores de uso. Dessa forma, podemos mudar as regras do jogo nas negociações salariais coletivas de muitas manei- 
ras diferentes, mas temos que levar as regras preexistentes em conta e mostrar como eles são compatíveis ou incompatíveis com as novas regras (Torfing, 1999:64; tradução livre).

Isso é fundamentalmente o que os juízes comprometidos com o chamado direito como integridade fazem no campo da jurisdição. Assim, embora Dworkin insista que essa busca pela integridade deve resultar necessariamente num romance politicamente liberal, defendo que se compreendemos a integridade do Direito como um processo de articulação hegemônica e não de mediação liberal, a noção de direito como integridade de Dworkin proporciona a melhor compreensão das atividades judiciais para a ligação entre a teoria do discurso e as práticas judiciais no nível meso de análise.

Mesmo assim, conforme dito anteriormente, esta é uma afirmação que parece, à primeira vista, bastante controversa, já que criticando autores liberais como Rawls, Habermas e o próprio Dworkin, Mouffe ressalta o problema do pluralismo liberal se limitar à esfera privada, e reivindica um pluralismo mais radical, capaz de admitir também um pluralismo de regimes políticos (politeia). No entanto, mesmo tendo em conta estas críticas, as propostas políticas de Mouffe não são tão diferentes das dos liberais: enquanto os liberais, como Rawls, Habermas e Dworkin, reivindicam uma dimensão moral superior que unifica a comunidade política e ainda permite desacordos éticos e pessoais, Mouffe sugere um fundo ético-político com princípios capazes de unir as pessoas politicamente sem negar, contudo, suas convicções particulares plurais a respeito do que é bom (Mouffe, 1996:90-91).

Os princípios ético-políticos destacados por Mouffe seriam diferentes dos princípios de justiça rawlsianos, pois seriam mais abstratos do que os de Rawls. Eles também seriam diferentes dos procedimentos da democracia deliberativa de Habermas, já que seriam valores substantivos. Mas, como os princípios propostos por Mouffe são os princípios substantivos, mas abstratos, da liberdade e da igualdade que, por poderem ser interpretados de várias formas diferentes, permitiriam o pluralismo político, a sua proposta política acaba sendo próxima à de Dworkin. Inclusive, a ideia de "comunidade de princípios" dworkiniana, que não é mais do que uma associação política com base nos conceitos interpretativos da liberdade e da igualdade, parece ser uma base mais adequada para a democracia radical proposta por Mouffe, do que a noção de societas de Oakeshott - uma associação baseada mais em re- 
gras do que em princípios - que ela usa como exemplo de uma comunidade política unida, mesmo que respeitosa ao pluralismo (Mouffe, 1996:96).

Sedo assim, para além dos demais motivos citados anteriormente, com as ideias de Dworkin e Mouffe sobre a comunidade política sendo tão próximas, argumento que a teoria jurídica de Dworkin - com base em sua comunidade de princípios - é a teoria do Direito mais adequada para uma abordagem baseada nos fundamentos do pensamento de Mouffe que surgem a partir da ontologia social desenvolvida em seu trabalho com Laclau, Hegemonia y Estrategia Socialista. Com uma condição: se levarmos a sério o pluralismo radical, devemos entender a integridade do Direito não como uma mediação moral, mas como uma articulação política; não necessariamente como um meio para resultados liberais, mas como uma dimensão da luta pela hegemonia. Desta forma, a integridade do Direito não é necessariamente uma integridade moral liberal, como gostaria Dworkin, mas uma integridade política hegemônica.

\section{PARA UMA ANÁLISE DE CASOS EMPÍRICOS NO NÍVEL MICRO: REFLEXÕES SOBRE AS DECISÕES JUDICIAIS NO CONTEXTO DA JUDICIALIZAÇÃO DA POLÍTICA E POLITIZAÇÃO DA JUSTIÇA NO BRASIL}

Tendo em vista as observações teóricas acima, que tipo de investigação no nível micro poderia ser feita? Quanto a este ponto, gostaria de dar apenas alguns exemplos de "textos em si", retirados de decisões judiciais e que poderiam ser proveitosamente analisadas no âmbito de uma teoria do discurso. Considerando a realidade brasileira, destaco as decisões do Supremo Tribunal Federal (STF) sobre:

1) o direito a greve dos funcionários públicos $\left(\mathrm{MI}^{25}\right.$ 670, 708 e 712);

2) a possibilidade de pesquisas científicas com células-tronco (ADI ${ }^{26}$ 3.510); e

3) a fidelidade dos candidatos aos seus partidos políticos (ADI 3.999 e 4.086).

No primeiro caso, há o chamado "ativismo judicial", já que nesta decisão os juízes do STF fixaram os termos do direito de greve dos servidores públicos brasileiros, estabelecido pela Constituição, mas sem regulamento infraconstitucional. No segundo, há assunção, pelo poder Judiciário, da atividade de um "papado laico", na qual é decidido um di- 
lema moral polêmico, tradicionalmente resolvido em outras instâncias religiosas ou políticas. E no terceiro, há a intervenção judicial na competição política, exemplo clássico de "judicialização da política".

Essas três decisões são exemplos de três das mais controversas interferências judiciais no mundo político (Badinter e Breyer, 2004). E, como decisões propriamente políticas, creio que elas devam ser analisadas com relação às práticas hegemônicas que realizam internamente, ou seja, sua metonímia e sinédoque textual, apesar do peso que o espectro da catacrese de Montesquieu possa ter. E o que podemos perceber na análise textual dessas decisões? Infelizmente, não é possível realizar uma análise mais profunda de cada decisão no espaço deste artigo. De qualquer forma, existem algumas observações gerais importantes que devem ser destacadas e podem contribuir para a compreensão do papel político do Judiciário brasileiro contemporâneo, sob a luz da teoria do discurso de Laclau e Mouffe.

O que se pode inferir da análise das decisões é que, entre um entendimento do Direito como vinculado à unidade moral, e um entendimento do Direito vinculado à diversidade de preferências políticas, os juízes brasileiros se comportam atendendo ao chamado do primeiro entendimento, tão bem representado pela teoria de Dworkin. Porém, a unidade moral que esses juízes tentam representar em seus julgamentos não reflete a justiça liberal preconizada por Dworkin. Não se trata de uma justiça meramente formal, nem ligada à concretização dos procedimentos habermasianos: ela visa, como em Dworkin, a efetivação de princípios substantivos. Mas, diferentemente de em Dworkin, estes princípios não se esgotam nos cânones liberais.

Por exemplo, o, em tese, individualista princípio da proteção da dignidade humana ganha contornos solidários que fazem alguns ministros do STF reconhecerem dignidade no embrião humano, mas relativizarem essa dignidade em prol da dignidade de quem aguarda a cura de doenças que podem advir das pesquisas com células-tronco embrionárias. Este comportamento dos juízes mostraria, portanto, que, de fato, a dimensão de unidade moral para a regulação da atividade política não seria mais do que uma máscara para uma escolha política possível dentre várias? As críticas dos autores que chamam mais atenção para a dimensão social do dissenso, como pragmatistas, multiculturalistas, feministas e marxistas, seria, assim, mais correta do que o entendimen- 
to proposto por Dworkin? Haveria outra maneira de compreender este "desvio" dentro da cartilha dworkiniana?

O problema é que, de um lado, o aspecto mais profundamente normativo da teoria de Dworkin, que exige uma única resposta correta para os casos jurídicos, corre o risco de lançar as decisões judiciais, quando tomadas na esteira da efetivação de direitos sociais e coletivos, numa vala comum de decisões incorretas. E, do outro lado, uma visão do direito que não reconhece a possibilidade de fundamentação jurídica numa dimensão de consenso em torno de princípios leva a uma leitura da atuação dos juízes - que, tendo em vista as decisões analisadas, se esforçam por fundamentar suas escolhas distanciando-se do subjetivismo, relativismo e pragmatismo - capaz de conduzir a um "denuncismo" arrogante, no qual cabe ao analista destacar que os juízes fazem o jogo de um grupo dominante, mesmo que não tenham consciência disso, como se apenas o analista externo fosse capaz de compreender tal fenômeno, enquanto os operadores do direito reproduziriam ilusões de integridade, inclusive, para si mesmos, ou então, seriam apenas mal intencionados.

Contra estes dois extremos, o presente trabalho propõe integrar ao estudo do Direito a categoria hegemonia e uma concepção sinedótica do movimento político. Isto é, a totalidade, o universal, direciona a ação política em geral, e neste caso especificamente, a ação judicial, mas não como um pressuposto, e, sim, como um horizonte. Toda universalidade é, desta forma, uma particularidade que logra se representar como universal por conseguir reunir em torno de si uma série de demandas que conseguem emergir por encontrar nessa particularidade o mais adequado significado para um significante que, por representar uma totalidade impossível em última instância, é tendencialmente vazio. A coincidência, sempre precária e reversível, entre este significado particular e este significante da universalidade é o que Laclau considera como hegemonia. E o que a análise das decisões reforça é que uma leitura da jurisdição brasileira embasada nesta chave de compreensão ajudaria a compreender melhor a sistemática da atual judicialização da política que tem como corolário e como outro lado da mesma moeda uma politização da justiça.

O primeiro movimento presente numa configuração hegemônica, tal como caracterizada por Laclau, é o chamado "deslocamento", que pode ser entendido como uma "emergência do real", no sentido lacani- 
ano do termo real. Isto é, a sociedade é uma totalidade discursiva, mas que conta com uma realidade que a ultrapassa, que é a realidade que não faz parte da sociedade por não ter sido assimilada discursivamente, escapando, portanto, à compreensão. Esta realidade é o que Lacan chama de "real" que não se confunde com o "simbólico" que permite a intermediação inteligível dos seres humanos e as coisas em si. Isto não impede que o que escapa à simbolização, mesmo que não seja compreendido, cause efeitos. Essa "emergência do real", isto é, a emergência de eventos que não conseguem ser assimilados dentro de formações discursivas prévias, é o que Laclau considera um "deslocamento". É este deslocamento que instaura a instabilidade dentro dos discursos relativamente estáveis, sedimentados na sociedade e abre espaço para a ação política, propriamente transformadora. É ele que não somente requer a ação do sujeito, mas, sim, que permite esta ação, já que, superado este deslocamento pela assimilação discursiva dos elementos deflagradores da crise, o sujeito também passa a ser uma posição de sujeito dentro deste discurso que foi capaz de "domesticar" esta realidade que o excedia.

Dentre essas emergências do real, destaco no primeiro caso analisado, a demora legislativa. $O$ discurso de separação de poderes não entraria em xeque se dependesse apenas das previsões constitucionais, apesar da presença em seu bojo, desde o início, do mandado de injunção. Acontece que a reiterada recusa tanto do Legislativo, quanto do Judiciário - dentro do seu primeiro entendimento do mandado de injunção - em dar provimento ao gozo de um direito constitucionalmente garantido, gerou instabilidades num discurso jurídico em que, já sob o auspício de novas teorias políticas e jurídicas menos formalistas, figurava como um de seus elementos importantes a efetivação dos direitos constitucionalmente previstos. Essa mesma instabilidade se apresenta no segundo caso, em que o avanço da biomedicina fez com que o discurso tradicional de respeito à vida e à dignidade das pessoas dentro do Direito passasse a não dar conta dos avanços científicos sem distinguir, ou não, o status das pessoas já nascidas e o dos embriões. Já no terceiro caso, dentro de um sistema partidário em que o normal seria o candidato se manter no partido que o elegeu, a recorrente infidelidade partidária também se tornou um elemento de instabilidade desse discurso que precisava se transformar e definir melhor certos pontos - se o mandado pertence ao partido ou ao candidato - que, em tese, não precisariam entrar em conflito, mas que, de fato, estavam entrando. 
Uma das formas de assimilação discursiva do deslocamento, na obra de Laclau, é o antagonismo, em que uma posição diferencial passa a ser entendida como também um obstáculo a uma identidade à qual se contrapõe. Como já transparece no parágrafo anterior, esta assimilação enquanto antagonismo, base para a ação política, é o que aconteceu nos casos analisados. Quando a emergência do real é significada como algo além do controle da ação humana - derivada da vontade de Deus, da natureza, ou de um imperativo sistêmico, por exemplo - o espaço para a ação política e transformação dos discursos permanece fechada. Por exemplo, os servidores públicos poderiam entender que a não regulamentação do seu direito de greve derivava de uma demora normal dentro do sistema democrático e, assim, poderiam se manter passivos. Contudo, não foi o que se observou e esse deslocamento foi assimilado como antagonismo, abrindo-se às vias de transformação política e efetivando verdadeiros sujeitos sociais capazes de empreender transformações nos discursos típicos que buscavam configurar a situação em que se encontravam.

Dentro dessa lógica, no primeiro caso, a demora dos legisladores foi entendida como uma displicência legislativa que se oporia à concretização de direitos garantidos constitucionalmente, bloqueando-a. No segundo, com a possibilidade da destruição de embriões humanos para a realização de certas pesquisas, o progresso científico também passou as ser significado como opositor à garantia do direito à vida, igualmente constitucionalizado e juridificado. No terceiro, a migração partidária dos candidatos após as eleições passou a ser compreendida como um tipo de ação pragmática individual que bloqueava a consolidação de um regime democrático partidário.

Abria-se assim, em todos os casos, um espaço para a ação política, no sentido de ação que visa buscar hegemonia dentro de uma determinada configuração discursiva. Pois havia em todos eles um antagonismo - isto é, uma identidade entendida como bloqueadora de alguma outra - e também uma representação da plenitude ausente que permitia que cada uma daquelas demandas particulares se apresentasse como universal, falando em nome da Constituição (primeiro caso), da vida (segundo caso) e da democracia (terceiro caso). Em nem todos os exemplos essa articulação discursiva e movimento sinedótico logrou êxito e a hegemonia foi obtida no sentido pretendido por aqueles que mobilizaram o aparelho Judiciário. Mas em todos eles é possível compreen- 
der que houve uma ação política que via no Judiciário uma arena privilegiada para se desenrolar em direção à busca de hegemonia.

Assim, símbolos da uma plenitude ausente - como a igualdade, a liberdade, a dignidade, a ordem constitucional etc. - politizam o Direito, abrindo-o à necessidade de preencher com significados específicos esses significantes de tendencial vacuidade, da mesma forma que ocorre na disputa política parlamentar, nos movimentos sociais, na formação de identidades coletivas etc. e, consequentemente, reprimindo as alternativas discursivas que não conseguiram a hegemonia.

Logo, cabendo ao Judiciário a guarda da Constituição e estando constitucionalizados uma série de significantes de tendencial vacuidade, incluindo a Constituição em si, este Poder se abre à luta pela hegemonia e, por vezes, se mostra como estrategicamente privilegiado para tanto. Um exemplo claro são os chamados "casos quentes" que impõem à arena Legislativa custos altos dentro de uma lógica dependente de votos, excluindo sistematicamente dessa arena determinadas demandas. É onde se encaixa o primeiro e, em certo sentido, também o terceiro casos estudados. Outro exemplo reside em situações que pretendem reverter a hegemonia obtida alhures, apelando a um princípio constitucional contra uma decisão política majoritária já tomada no Legislativo. O segundo e, mais uma vez, em certo sentido, o terceiro casos estudados podem ser entendidos como representantes dessa situação.

Isso tudo não impede, por certo, que, por mais que a teoria da hegemonia, tal como desenvolvida por Laclau e utilizada neste estudo, seja pensada num nível de abstração capaz de abarcar a ação política em todos esses modelos, existam diferenças de um modelo para o outro e existam especificidades nas práticas hegemônicas, por exemplo, dentro das instituições jurídicas e legislativas ou das instituições jurídicas e dos movimentos sociais. Neste sentido, e sem se afastar muito do que foi observado no modo de operação dos juízes nas decisões estudadas, a busca pela integridade pode e deve existir. No entanto, essa busca pela integridade torna-se dependente de um princípio de leitura que direcionará o romance em cadeia numa direção e não em outra, pois as marcas das decisões políticas pretéritas serão sempre símbolos e, enquanto tais, sobredeterminados de sentido e passíveis de hegemonização.

\section{CONSIDERAÇÕES FINAIS}

Partindo da caracterização de Montesquieu dos juízes como a "boca da lei", defendi que essa catacrese clássica não seria uma boa referência 
para a compreensão da atividade jurisdicional contemporânea. Em um contexto de crise da caracterização formalista do Direito, argumentei que uma abordagem alternativa para compreender Direito e as atividades judiciais poderia ser a teoria do discurso de Laclau e Mouffe. Assim sendo, a catacrese de Montesquieu deveria ser abandonada e outras figuras de linguagem que surgem das obras de Laclau e Mouffe poderiam ser melhores fontes de caracterização do Direito. Estas figuras de linguagem seriam a metonímia e sinédoque que Laclau e Mouffe usam para ilustrar o movimento de hegemonia política.

Tendo isto em vista, se a argumentação ao longo do texto é suficientemente fundamentada, ela mostra como a abordagem proposta pode ser útil para uma nova compreensão do Direito num contexto atual de crise. E não só num contexto de crise do Direito - incapaz de se encaixar exatamente em sua caracterização tradicional legalista - mas também num contexto de crise da representação política e da democracia, já que a judicialização da política é reforçada nos momentos em que a representação legislativa tradicional enfrenta problemas.

Destaco assim, que uma abordagem pós-estruturalista, como a teoria do discurso de Laclau e Mouffe, pode lançar nova e importante luz sobre esta crise. Noções como hegemonia, significantes vazios e deslocamento poderiam ajudar a compreender as novas articulações contemporâneas entre o político e jurídico. Isto seria verdadeiro no que diz respeito à dimensão de uma relação mais aberta entre as instituições jurídicas e o ambiente político e social (no contexto de um direito responsivo), como nas tentativas dos juristas para fazer do direito um todo integrado sob princípios comuns (como descrito no direito como integridade de Dworkin). Este é o caso mesmo para a análise do texto das próprias decisões judiciais (como nos estudos de caso citados), abrangendo também, é claro, as relações entre todas estas dimensões macro, meso e micro, como influenciadas umas pelas outras.

Em suma, relevante e útil para uma sociologia da prática judicial, a teoria desenvolvida por Laclau e Mouffe pode abrir espaço para novos e fecundos estudos do direito contemporâneo, embasando análises de discurso que podem esclarecer os jogos de poder que têm lugar nos antagonismos que encontram expressão no debate judiciário. Como apontado pelos próprios Laclau e Mouffe, é preciso saber "pelo que se está lutando e que tipo de sociedade se quer estabelecer". E isto requer "uma compreensão adequada da natureza das relações de poder e da 
dinâmica da política", já que "o que está em jogo é a construção de uma nova hegemonia" (Laclau e Mouffe, 2006:20). Ao fim e ao cabo, este artigo tentou, acima de tudo, trazer a aplicação destas orientações também para a análise da política feita no Judiciário e demais instituições jurídicas.

(Recebido para publicação em julho de 2012) (Reapresentado em junho e em setembro de 2013) (Aprovado para publicação em outubro de 2013) 


\section{NOTAS}

1. Quando utilizo a palavra Direito, com letra maiúscula, mesmo que não no início da frase, refiro-me ao campo de conhecimentos e práticas que se caracterizam pela referência à palavra. Já a palavra direito, sem o início em letra maiúscula, fará referência a determinados sistemas jurídicos ou prerrogativas jurídicas específicas.

2. O que chamo aqui de aplicação silogística da lei é o raciocínio jurídico básico de que se se observa faticamente a norma prevista em lei, deve ser aplicada aquela sanção igualmente prevista em lei. Por exemplo, explicitando isso num silogismo claro, digamos que premissa 1 diz que quem mata outra pessoa deve ser preso por 30 anos e premissa 2 diz que determinado sujeito matou alguém. Logo, a conclusão do silogismo é a de que determinado sujeito deve ser preso por 30 anos.

3. Catacrese é uma figura de linguagem que usa uma metáfora desgastada para caracterizar algo que determinada língua não designa com uma palavra específica, como nos casos de "perna da cadeira" ou "asa da xícara".

4. A prosopopeia é uma figura de linguagem usada quando são dadas a animais ou objetos inanimados características dos seres humanos, como nas expressões "o galo canta" ou "o violão chora".

5. Garapon destaca a imprecisão desta abordagem sobre o direito perante determinados desenvolvimentos jurídicos contemporâneos. No entanto, esse problema sempre foi notado por pontos de vista críticos a um formalismo jurídico estrito, como, por exemplo, a abordagem do Direito Natural e dos Estudos Jurídicos Críticos, ou mesmo o positivismo jurídico de autores como Hans Kelsen que, ainda que focando o elemento formal das normas jurídicas no que tange à pretensão analítica do positivismo - a pretensão de uma teoria pura do direito - sempre reconheceu que, no que tange à dimensão prática do direito, a norma jurídica produzida pela jurisdição sempre complementou a "moldura" exposta na lei com algum elemento volitivo de conteúdo moral e político. Logo, tal problema derivado de uma compreensão legalista e formalista do Direito pode ser considerado uma imprecisão conceitual e não uma crise de caráter histórico. Ainda assim, é possível entendê-la como um problema conceitual que tem sido, cada vez mais, posto em destaque por transformações sociais e políticas que ocorreram nos últimos anos, permitindo-nos enxergá-la como uma crise atual. Para um exemplo de estudo que compreende o fracasso das abordagens formalistas do direito como um problema conceitual, mas radicalizado por mudanças sociais e políticas relativamente recentes e, portanto, afetado por uma crise contemporânea, como estou considerando neste artigo, ver Capelletti (1993).

6. Metonímia é uma figura de linguagem utilizada na substituição de uma palavra por outra que está relacionada com a palavra substituída por uma relação de contiguidade, substituindo o recipiente pelo conteúdo (e vice-versa), o autor por seu trabalho (e vice-versa), o efeito por sua causa (e vice-versa) etc. Já a sinédoque é um tipo específico de metonímia na qual o conjunto é substituído por um dos seus componentes, ou vice-versa.

7. A noção de significante vazio e outras categorias laclaunianas se tornarão mais claras adiante. 


\section{Igor Suzano Machado}

8. Aqui se explicita o caráter de sinédoque da política no pensamento de Laclau e Mouffe, e, ao longo da argumentação do artigo, espero deixar clara a relação entre esse caráter e o direito atual.

9. O contexto de "judicialização da política" é caracterizado por uma diminuição das fronteiras e diferenças entre as funções do governo, neste caso representadas pelas funções legislativas e judiciárias. Sobre o fenômeno contemporâneo da "judicialização da política", ver Tate e Valinder (1995).

10. Aqui, faço uso da distinção heideggeriana, assimilada por Laclau e Mouffe, em que o "ôntico" se refere às manifestações concretas de certos seres, enquanto o "ontológi$\mathrm{co}^{\prime \prime}$ se refere a uma origem mais abstrata e fundamental desses seres. Para deixar o ponto mais claro, podemos dizer, por exemplo, que as reflexões das teorias políticas e sociais dizem respeito à dimensão ontológica da política e da sociedade, enquanto as pesquisas em sociologia e ciência política se referem às manifestações ônticas desses fenômenos.

11. Este referência dworkiniana é o que permite a referência a "um romance bem conhecido" no título desta seção.

12. É por isso que Laclau não se concentra na "sociedade", mas no "social", isto é, as relações que tentam dar à sociedade um sentido estável provisório, como um todo inteligível. A dimensão do "social" e suas diferenças com relação à dimensão do "político" serão melhor explicadas na próxima seção do artigo.

13. Pode ser considerado como exemplo desse pragmatismo, o pragmatismo de Richard Posner. Trata-se de um destacado pragmatista jurídico norte-americano que ressalta as insuficiências do formalismo jurídico e o relativismo de valores morais para apoiar o uso de critérios econômicos como o principal fundamento das decisões judiciais. Ver Posner (2007).

14. Conforme ficará mais claro adiante, trata-se da opção de Ronald Dworkin em sua teoria do direito como integridade.

15. Enquadrando a atividade política no pensamento dos autores, pode-se dizer que "a política", em Laclau e Mouffe, equivale às práticas, em nível ôntico, que visam articular os anatogonismos presentes no que eles chamam de "o político" no nível ontológico.

16. Em Gramsci, porém, esta particularidade que pode representar a universalidade só pode ser o proletariado, pois para ele a economia é o fundamento último da sociedade, sendo, por conseguinte, as classes sociais os únicos sujeitos que realmente poderiam transformá-la. Mas a centralidade da economia, diferentemente do que encontramos em Gramsci, é negada por Laclau e Mouffe.

17. Aqui eu uso a distinção da semiótica entre significantes - os símbolos - e significados - os conteúdos, eventualmente diferenciados, de contexto para contexto, que podem ter esses símbolos.

18. O que chamo aqui de positivimo inclusivo é uma das vertentes do positivismo jurídico contemporâneo, caracterizado por tentar responder as críticas que Dworkin dirigiu ao modelo de positivimo de H. L. A. Hart. O positivismo, tradicionalmente, voltou sua compreensão do fenômeno jurídico para sua dimensão "formal": mesmo admitindo a importância da dimensão substantiva da norma jurídica, inclusive no que tange à vontade do aplicador da lei, o positivismo sempre entendeu como característica fundamental do Direito seus aspectos formais e daí derivou suas principais teses 
sobre a validade da norma enquanto norma jurídica. O desafio, feito por Dworkin, de incorporação necessária de princípios morais na caracterização do Direito ensejou duas respostas posivistas: a resposta exclusiva - o direito nunca depende da moral para caracterizar suas próprias normas - de que é expoente a obra de Joseph Raz,e a resposta inclusiva - o Direito não depende necessariamente da moral para caracterizar suas próprias normas, mas pode, se convencionalmente aceito, exigir como critério de validade de suas normas, determinado conteúdo moral - de que é expoente a obra de Jules Coleman. Entendendo a convenção que estipula a formulação de normas jurídicas na tradição romano-germânica como a promulgação da legislação pelo poder Legislativo, o positivismo inclusivo poderia assim, aceitar que valores morais substantivos determinem a validade ou não da norma jurídica, desde que, no entanto, tais valores estejam explícitos na legislação, como por exemplo, nas cartas constitucionais. Um exemplo dessa abordagem pode ser o "garantismo" de Ferrajoli, influência importante de muitos estudos sobre o direito penal no Brasil. Para Ferrajoli, adaptar o positivismo jurídico a uma matriz menos formal, aceitando como guia, para o reconhecimento da natureza jurídica de uma norma, sua adequação a princípios morais, é possível desde que esses requisitos morais sejam o que conhecemos como as garantias constitucionais - daí a intitulação de sua teoria de "Garantismo". Nesse sentido, ver Ferrajoli (2009).

19. A noção de direito como integridade de Dworkin se assenta sobre a tese de que, ao contrário do que sustentaria o positivismo jurídico, a relação entre a moral e o Direito não é contingente, e, sim, necessária, sendo, portanto, mais importante do que as regras derivadas dos textos legais, os princípios morais que fundamentam estas regras. A noção de direito como integridade será melhor explicada neste artigo, na sessão intitulada Direito e Sociedade em Transição no Nível Macro: Reflexões sobre as Instituições Judiciais. De qualquer maneira, para uma referência fundamental sobre o tema, ver Dworkin (2003).

20. Ver nota 13.

21. Ver a distinção feita no início desta seção entre o "social" e o "político" em Laclau e Mouffe, e sua relação com as dimensões de "sedimentação" e "reativação" do discurso.

22. Ver nota 18.

23. Os tipos ideais são construções intelectuais em que algumas características particularmente importantes de um objeto específico - uma instituição social, uma relação social ou uma ação social - são radicalizadas para permitir que o analista compreenda a sua manifestação concreta, comparando os fenômenos observados com a construção conceitual que desenvolveu idealmente. A metodologia dos tipos ideais foi criada por Max Weber, clássico da Sociologia que Nonet e Selznick usam neste ponto como referencial metodológico.

24. É necessário destacar que tal alegoria também se mostra especialmente útil para uma abordagem discursiva das práticas judiciais, já que a metáfora do romance, utilizada por Dworkin, mostra-se como uma ilustração bastante proveitosa de um discurso, mesmo se reduzimos a categoria discurso ao plano da fala e escritura.

25. MI = Mandado de injunção. É um tipo de ação constitucional em que é solicitada uma resposta judicial a um vácuo legislativo.

26. $\mathrm{ADI}=$ Ação Direta de Inconstitucionalidade. É um dos meios de controle de constitucionalidade das leis no Brasil, um processo em que é pedida uma declaração judicial sobre a inconstitucionalidade de determinada lei aprovada pelo Legislativo. 


\section{REFERÊNCIAS BIBLIOGRÁFICAS}

BADINTER, Robert e BREYER, Stephen (orgs.). (2004), Judges in Contemporary Democracy. New York/London, New York University Press.

CAPELLETTI, Mauro. (1993), Juizes Legisladores? Porto Alegre, Sergio Antonio Fabris Editor.

DWORKIN, Ronald. (2003), O Império do Direito. São Paulo, Martins Fontes.

. (2006), Justice in Robes. Cambridge/London, The Belknap Press of Harvard University Press.

FERRAJOLI, Luigi. (2009), Garantismo: Una Discusión sobre Derecho y Democracia. Madri, Editorial Trotta.

FOUCAULT, Michel. (2007), A Arqueologia do Saber. (7a ed.). Rio de Janeiro, Forense Universitária.

GARAPON, Antoine. (2001), O Juiz e a Democracia: O Guardião das Promessas. (2a ed.). Rio de Janeiro, Revan.

HOWARTH, David. (2004), "Hegemony, Political Subjectivity, and Radical Democracy”, in S. Critchley e O. Marchant (orgs.), Laclau: A Critical Reader. New York, Routledge, pp. 256-276.

LACLAU, Ernesto. (1996), Emancipation(s). London, Verso.

. (1998). "Desconstrucción, Pragmatismo, Hegemonía", in C. Mouffe (org.), Desconstrucción y Pragmatismo. Buenos Aires, Paidós, pp. 97-136.

. (2000), Nuevas Reflexiones sobre la Revolución de Nuestro Tiempo. (2ed.). Buenos Aires, Ediciones Nueva Visión.

. (2004a). "Construyendo la Universalidad", in J. Butler; E. Laclau e S. ãiãek (orgs.), Contingencia, Hegemonía, Universalidad: Diálogos Contemporáneos en la Izquierda. Buenos Aires, Fondo de Cultura Económica de Argentina, pp. 281-306.

. (2004b), “Glimpsing the Future”, in S. Critchley e O. Marchant (eds.), Laclau: A Critical Reader. New York, Routledge, pp. 279-328.

. (2007), La Razón Populista. Buenos Aires, Fondo de Cultura Económica.

e MOUFFE, Chantal. (2006), Hegemonía y Estrategia Socialista: Hacia una Radicalización de la Democracia. (2a ed.). Buenos Aires, Fondo de Cultura Económica de Argentina.

LEFORT, Claude. (1986), “La Question de la Démocracie”, in C. Lefort, Essais sur le Politique. XIXe e XXe Siècles. Paris, Éditions du Seuil, pp. 17-32.

MOUFFE, Chantal. (1996), O Regresso do Político. Lisboa, Gradiva.

MONTESQUIEU, Baron de. (2001), The Spirit of Laws [electronic resource]. Kitchener, Fantoche.

NONET, Philippe e SELZNICK, Philip. (2010), Direito e Sociedade: A Transição ao Sistema Jurídico Responsivo. Rio de Janeiro, Revan.

POSNER, Richard. (2007), Problemas de Filosofia do Direito. São Paulo, Martins Fontes. 
TATE, C. Neal e VALINDER, Torbjörn (eds.). (1995), The Global Expansion of the Judicial Power. New York/London, New York University Press.

TORFING, Jacob. (1999). New Theories of Discourse: Laclau, Mouffe and ãiãek. Oxford, Blackwell Publishers.

WARRINGTON, Ronnie; DOUZINAS, Costas e McVEIGH, Shaun. (1991), Postmodern Jurisprudence: The Law of Text in Texts of Law. London, Routledge. 


\section{ABSTRACT \\ Jurisdiction, Hegemony and Integrity: A Post-structuralist Approach to Law and its Relation with Society and Politics in Brazil}

This article aims to link the theory of discourse developed by Laclau and Mouffe to the analysis of contemporary law. According to the proposed by the article, contemporary law is victim of a crisis that destabilizes its foundations, justifying their study under a post-structuralist approach. For this task, the article mobilizes the notion of hegemony developed by Laclau and Mouffe, but links the abstract reflections of the authors about society in general with three dimensions of legal phenomena in particular: 1 . The judicial institutions and their relationship with the socio-political environment, 2. The practices of jurisdiction and litigation, and 3. The judicial decision itself. For the first dimension, I will use the work of Nonet and Selznick. For the second, I will take the legal theory of Dworkin. And, for the third, I will make reference to some important recent decisions of Brazilian Supreme Court.

Key-words: Law; society; politics; hegemony; Laclau and Mouffe

\section{RÉSUMÉ}

Juridiction, Hégémonie et Intégrité: Une Optique Post-structuraliste sur le Droit et son Rapport à la Société et à la Politique au Brésil

Dans cet article, on cherche à relier la théorie du discours proposée par Laclau et Mouffe à l'analyse du droit contemporain. Il y est proposé que le droit contemporain serait victime d'une crise qui ébranle ses fondements, ce qui justifierait qu'il soit étudié sous un angle post-structuraliste. Ainsi, cette recherche se sert de la notion d'hégémonie de Laclau et Mouffe, mais tout en associant leurs réflexions abstraites sur la société en general, à trois dimensions du phénomène juridique en particulier, les institutions judiciaires et leur relation avec le milieu sociopolitique, les pratiques de juridiction et litiges et la décision judiciaire en soi. La première dimension s'appuie sur le travail de Nonet et Selznick. La deuxième sur la théorie juridique de Dworkin. Et la troisième se rapportera à certaines décisions récentes et importantes du Suprême Tribunal Fédéral brésilien.

Mots-clés: Droit; société; politique; hégémonie; Laclau et Mouffe 